\title{
High School Pupils' Academic Achievement, Self-regulation (Locomotion and Assessment), and Psychological Well-Being
}

Danilo Garcia $^{1,2 *}$, Alexander Jimmefors ${ }^{2,3}$, Lillemor Adrianson ${ }^{2,4}$, Fariba Mousavi ${ }^{2}$, Patricia Rosenberg $^{2}$, Trevor Archer ${ }^{2,3}$

${ }^{1}$ Centre for Ethics, Law and Mental Health, University of Gothenburg, Gothenburg, Sweden ${ }^{2}$ Network for Empowerment and Well-Being, Sweden

${ }^{3}$ Department of Psychology, University of Gothenburg, Gothenburg, Sweden

${ }^{4}$ Department of Pedagogy and Behavioral Sciences, University of Borås, Borås, Sweden

* Correspondence concerning this article should be addressed to D. Garcia, CELAM,

University of Gothenburg, Wallinsgatan 8, SE 43141 Mölndal, Sweden. E-mail:

danilo.garcia@neuro.gu.se; danilo.garcia@euromail.se 


\begin{abstract}
Background: Education plays an important role on a personal level because it is related to personal control, a healthy lifestyle, greater income, employment, interpersonal relations, and social support (Mirowsky \& Ross, 2003). Self-regulation is the procedure implemented by an individual striving to reach a goal and consists of two inter-related strategies: (1) the identification of the desired out-come and the appraisal of procedures to reach the desired goal (i.e., assessment), and (2) the selection between available approaches to reach the goal and the commitment to the chosen approaches until the goal is reached (i.e., locomotion) (Kruglanski et al, 2000). Self-regulation plays an essential role in academic achievement (Kruglanski et al 1994, 2000). Psychological well-being is a multi-faceted concept composed of six different intra-personal characteristics that describe the fully functional individual (Ryff, 1989). These factors are: positive relationships with others, self-acceptance, environmental mastery, autonomy, purpose in life, and personal growth. We aimed to study the relationship between academic achievement and self-regulation and psychological wellbeing in Swedish high school pupils.
\end{abstract}

Method: Participants were 160 Swedish high school pupils (111 boys and 49 girls) with an age mean of 17.74 (sd = 1.29). We used the Assessment and Locomotion Scales (Kruglanski et al., 2000) to measure self-regulation and Ryff's Psychological Well-Being Scales short version (Clark et al., 2001) to measure well-being. Academic achievement was operationalized through pupils' final grades in Swedish, Mathematics, English, and Physical Education. The courses take place during either one or two semesters and the grading scale ranges from $\mathrm{F}=$ fail to $\mathrm{A}=$ pass with distinction.

Results: Final grades in Swedish were positively related to two psychological well-being scales: self-acceptance and personal growth; and to the self-regulation strategy of assessment. Final grades in Mathematics were positively related to three psychological well-being scales: self-acceptance, autonomy, and personal growth; and also to assessment. Final grades in English were positively related to one psychological well-being scale: personal growth; and also to assessment. Final grades in Physical Education were positively related to four psychological well-being scales: environmental mastery, self-acceptance, autonomy, and personal growth; and also to the self-regulation strategy of locomotion.

Conclusions: A profile consisting of assessment orientation combined with self-acceptance and personal growth leads to the best study results. This understanding is important when supporting pupils in achieving the best possible results in school and thus lay the formation for a continued successful life.

Key Words: Academic Achievement; Assessment; Grades; Locomotion; Psychological WellBeing; Self-regulation. 
Education plays an important role from a social perspective because it increases a nations' standard of living (Kessler el al., 1995). On a personal level it creates personal control (i.e., one aspect of an individual's psychological well-being), a healthy lifestyle, greater income, employment, interpersonal relations and social support (Mirowsky \& Ross, 2002). In Sweden, 23.1 percent of the pupils who finish ninth grades didn'tpass all of their subjects in the year 2012/13 (Skolverket, 2012). That is slightly higher than the year before when 22,6 percent didn't pass all the subjects. It is important that people who work with any form of education, for example, teachers and other personnel in the educational system have knowledge of different aspects that increases students' grades. Based on previous research, psychological well-being and self-regulation might play essential roles influencing academic achievement (Kruglanski et al., 1994, 2000).

\section{Psychological well-being}

The focus of earlier well-being research has been on physical and material constructs (Ryff, 1995). Physical well-being is understood as good physical health without physical illness and a strong well functioning body. The assessment of a person's physical health is conducted through a series of medical and biological examinations to preclude any physical illness. Material health is understood as a person's availability to a home, transportation, and healthy food to attain and preserve a person's well-being. Psychological health, however, is harder to assess because of its complexity.

Psychological well-being is a multi-faceted concept which cannot be measured by any single variable. There are a numbers of different descriptions and ways to measure psychological well-being, it this study Ryff's (1989) theory of psychological well-being have been used. Ryff (1989) proposed a multidimensional model, based on work by Jahoda among others, composed of six different factors that when measured together would provide an understanding of the psychological well-being of an individual in it's entirety. According to 
Ryff (1989), Jahoda's work tried to study and describe what it meant to have psychological health, based on earlier psychological theories such as Erikson's psychological stages, Maslow's theories of self-actualization Allport's formulation of maturity , Rogers' description of a fully functioning individual, and Jung's account individuation . According to Ryff (1989) the work of Jahoda had small impact on the current well-being research because of the lack of valid and reliable assessment measures. Ryff (1989) suggested that these perspectives could be integrated into one; psychological well-being. Ryff's theory does not focus on the absence of negative characteristics, as many other's, but of the occurrence of positive characteristics. These characteristics are; self-acceptance, positive relationships with others, autonomy, environmental mastery, purpose in life and personal growth (Ryff, 1989; 1995). According to Ryff (1989) the most central part of well-being is a person's sense of self-acceptance, which is an attribute of mental health but also a characteristic of selfactualization, optimal functioning and maturity because it refers to a person's ability to accept the good and bad sides of their personality. Ryff (1989) also concluded that the ability to love and have positive relations with other people is a central part of good mental health. She also found that being resistant to peer pressure and spending little time seeking approval from other people (i.e., autonomy) is an important part of well-being. The next factor in Ryff's theory of well-being is environmental mastery which refers to a person's ability to change, choose and design his or her environment to fit his or her conditions. Ryff also claimed that well functioning individuals have goals, desires and a feeling that they have a purpose in life. Another important part of Ryff's theory of psychological well-being is personal growth, which depicts seeing life as an opportunity for growth by engaging in different challenges (Ryff, 1989). 


\section{Self-regulation}

Self-regulation is the procedure implemented by an individual who is striving to reach a goal. The individual must first identify the desired out-come, then choose how to operate to reach the desired goal. Thereafter the individual needs to assess and decide between available approaches to reach the goal and then stay committed to the chosen strategies until the goal is reached. Kruglanski and colleagues (2000) differentiate between the steps of self-regulation: identification of goal, identification of strategies to reach the goal, action, and maintenance of action. According to... Self-regulation is then structured into two main concepts: assessment (1) referring to the initial part of the self-regulation process when the individual assess, compare and appraise possible goals and procedures needed to attain these goals and locomotion (2) referring to the action-based part of self-regulation when the individual adhere to a step-by-step approach until the goal is reached (Kruglanski et al, 2000). These processes can be illustrated by an example: an adolescent who is trying to achieve a good grade in order to acquire an education. The first step (assessment) is to gather all the necessary information that is important to achieve good grades, then choosing which test is most important to start studying for and choosing the best studying strategy. After gathering all the data that is necessary for studying for the test, there is the stage of actually starting to study for the test (i.e., locomotion). Locomotion can be described as the action mode that helps the pupil start studying and to keep doing it even though she/he would rather do something else, and to actually show up for the examination.

Unlike Rubicon's action model of action phases (Gollwitzer, 1990; Heckhausen, 2000), Kruglanski and colleagues (2000) and Higgins and colleagues (2003)have studied locomotion and assessment separately and conceptualized them in accordance to Lewin's distinction between setting a goal and striving for it (Lewin, Dembo, Festinger, \& Sears, 1944). Assessment and locomotion are suggested as processes that work together in order to 
help a person to achieve a working goal. Kruglanski et al. (2000) urged that assessment and locomotion should be seen as two separate and individual personality orientations, both influencing self-regulation (Higgins et al, 2003; Kruglanski et al, 2000). If a person has an assessment orientation he or she tends to reflect and assess different possible pathways and goals. This type of person often evaluates his- or herself, his personality and behavior. A person who has a locomotion orientation does not have the same need for evaluating and assessing (Kruglanski et al, 2000). Instead, these individuals' primary focus lie on achieving goals and moving forward. These individuals don't spend much time on reflection and evaluation of different pathways on how to achieve goals, as the Nike slogan says; they just do it (Kruglanski et al., 2000).

Kruglanski and colleagues (2000) and Higgins and collegues (2003) found that assessment was positively correlated with depression and anxiety and negatively correlated with self-confidence and optimism. Locomotion on the other hand correlated positively with self-confidence and optimism, and negatively with anxiety and depression (Kruglanski et al, 2000). Pierro and colleagues (2012) found similar results showing positive correlations between locomotion and the individual's sense of work-related satisfaction. Moreover, there is a relationship between locomotion and extrovert behavior (e.g, the ability to socialize with others, positive affectivity), motivation, type-A behavior, readiness for action, and vitality (Higgins et al., 1997; Kruglanski et al., 2000), and higher well-being (Giacomantonio, Manetti \& Pierro, 2012). These findings are in line with recent research conducted among high school pupils showing that adolescents with high levels of negative affect report being higher in assessment compared to adolescents with low levels of negative affect, while adolescents with high levels of positive affect report higher levels of locomotion compared to adolescents with low levels of positive affect (Jimmefors, 2013). 
In sum, the tendency to constantly evaluate one self, which is typical for the assessment oriented person, leads to a sense of inadequacy, negative emotions, lower selfesteem and less optimism (Kruglanski et al, 2004). Locomotion on the other hand is understood as activation and forward striving where the individual is spending little time reflecting. The main focus is in moving forward towards a goal, which results in more positive emotions and higher optimism and self-confidence (Kruglanski et al, 2004). It might be expected that locomotion, in contrast to assessment, should be positively related to positive health measures such as psychological well-being.

\section{Academic Achievement}

Kruglanski and colleagues (2000) tested how self-regulation influences academic achievement. The authors tested 665 high school pupils and found that the individuals who where high in both assessment and locomotion had the highest score in their grade point average. Moreover, earlier research regarding self-regulation and academic achievement has suggested a pedagogical method that predicts higher academic achievement, called selfregulated learning (Corno \& Mandinach, 1983; Corno \& Rohrkemper, 1985), which is based on three components. The first component comprises different cognitive strategies for planning, monitoring and modifying one's different thoughts and cognitions (Pintrich \& V. De Groot, 1990). The second component is how well an individual can control her/his own effort regarding schoolwork and performance. For example, trying to complete a difficult task next to a noisy classmate. A pupil who feels in control can block out the classmate and focus on the difficult assignment. The third component of self-regulated learning is the different cognitive strategies the pupil uses to learn, remember and understand the knowledge the teachers intend to teach (Pintrich \& V. De Groot, 1990). For instance, rehearsal, elaboration and developing learning strategies have proved to result in higher achievement (Pintrich\& V. De Groot, 1990). There are similarities between the principle of self-regulation 
and self-regulated learning; self-regulated learning refers to different cognitive strategies to maximize the learning such as planning, monitoring and modifying one's thoughts and cognitions, as well as evaluating different ways to complete a goal; these components are also different parts of the assessment orientation. However, self-regulated does not include the locomotion construct. Thus, it onlysuggests a positive relationship between the assessment orientation and academic achievement.

As far as we know, there is no research about psychological well-being and academic achievement. Battenburg-Eddes and Jolles (2013), however, investigated how emotion is related to pupils' underachievement in school. The authors investigated 556 Dutch pupils and found that low emotional well-being predicts academic underachievement. However, these researchers operationalized emotional well-being by asking pupils questions such as: "I feel good and often I am happy”, "Quite often I am angry, sad, tense, or in a bad mood," "Lately, I don't feel as good as I used to", "I am satisfied with the things I do and the way I do these things", "I like going to school", "I often feel sick," "I get a lot of headaches" (Battenburgeddes and Jolles, 2013). Although important, this operationalization of well-being is different to Ryff's psychological well-being (Kjell, Nima, Sikström, Archer \& Garcia, 2013).

Bandura (1977) introduced self-efficacy as a person's belief in the own capacity to achieve a goal or a specific outcome. A person with a high sense of self-efficacy has belief in hers/his ability to overcome future obstacles that are in the way of hers/his goals (Bandura, 1977, 1982). Pintrich and V. De Groot, (1990) suggested that pupils with high self-efficacy achieve higher grades and better results on different tasks in school, seatwork, exams, quizzes, essays, reports and higher grades. Self-efficacy is also positively related to psychological well-being (Ryff, 1989), which in turn is positively related to positive affect (Garcia, Archer, Moradi \& Andersson-Arntén, 2012). On this basis it is possible that high 
psychological well-being is positively related to higher grades because its relation to positive affect (Garcia et al., 2012) and self-efficacy (Ryff, 1989).

\section{The present study}

The present study aims to investigate if the two self- regulation orientations (i.e., locomotion and assessment) and psychological well-being are related to high school pupils' academic achievement (i.e., final grades in Swedish, English, Mathematics, and Physical Education). Despite early study's, showing that both assessment and locomotion lead to higher academic performance, pedagogical methods, such as, self-regulated learning stress the link between assessment orientation (i.e., with a need for reflection and evaluation) and higher grades. An exception might be expected regarding grades in Physical Education, because of its moving and action orientated nature. In this case locomotion might predict better grades. The hypotheses are as follows:

1. High assessment orientation is expected to be positively related to higher grades

2. High locomotion orientation is expected to be positively related to higher psychological well-being

3. High levels of psychological well-being were expected to be positively associated to higher grades.

\section{Method}

\section{Participants and Procedure}

Participants were 160 Swedish high school pupils (111 boys and 49 girls) with an age mean of $17.74(d s=1.29)$. The pupils came from two different schools in the Swedish west coast. The first school had five hundred pupils and is situated in Gothenburg. The second school is located in a smaller city with eight hundred pupils. Because of the different geographic locations, the pupils' social backgrounds are varied. The principals where informed about the PeerJ PrePrints | http://dx.doi.org/10.7287/peerj.preprints.219v1 | CC-BY 4.0 Open Access | received: 24 Jan 2014, published: 24 Jan 2014 
study and then confirmed the retrieving of the grades. The pupils were selected by the criteria of being at least 18 years of age, because of legal complications with pupils under this age (e.g., parent consent). The tests were completed online using a link that was sent by email to the respondents. The session took place during the students' original classes, and it took about forty minutes to complete the test. Pupils were briefly informed about the test (e.g., confidentiality, right to drop out at any time, etcetera) .In the first school everyone who participated received a cinema ticket, while in the second school the participants took part of a lottery for the remaining tickets. The pupils were asked to provide their social security number in order to match their answers with their final grades. The grades were collected by personnel at the schools and were send to the author in an Excel file.

\section{Measures}

Self-regulation. The Swedish version of the Regulatory Mode questionnaire (Kruglanski et al., 2000), earlier used by Jimmefors (2013), was used to assess self-regulation orientations. The test consists of 30 items measured on a 6 point likert scale (from $1=$ strongly disagree to 6= strongly agree) measuring assessment (e.g., " I spend a great deal of time taking inventory of my positive and negative characteristics", "I am a critical person”) and locomotion ("I am a doer', ' When I get started on something, I usually persevere until I finish it”). In the present study Cronbach's alphas were .75 for assessment and .74 for locomotion. See Appendix 1.

Psychological well-being. The Swedish version (Garcia \& Siddiqui, 2009) of Ryff's short test (Clarke, Marshall, Ryff Wheaton, 2001) was used to operationalize psychological well-being. The test consists of 18 items with a 6 point likert scale (from $1=$ strongly disagree to 6 strongly agree) measuring the six dimensions of psychological well-being: Autonomy (e.g., "I have confidence in my opinions, even if they are contrary to the general consensus"; Cronbach's alpha = .36), Environmental Mastery (e.g., "In general, I feel I am in 
charge of the situation in which I live"; Cronbach's alpha = .68), Personal Growth (e.g., "I think it is important to have new experiences that challenge how you think about yourself and the world"; Cronbach's alpha = .44), Positive Relations with Others (e.g., "People would describe me as a giving person, willing to share my time with others"; Cronbach's alpha = .42), Purpose in Life (e.g., "Some people wander aimlessly through life, but I am not one of them"; Cronbach's alpha $=.17$ ), and Self-Acceptance (e.g., "I like most aspects of my personality"; Cronbach's alpha $=.74)$. In the present study the whole scale showed a Cronbach's alpha $=.79$. See Appendix 2.

Academic achievement. This variable was operationalized through pupils' final grades in Swedish, Mathematics, English, and Physical education. The courses take place during either one or two semesters and the grading scale ranges from $\mathrm{A}=$ pass with distinction to $\mathrm{F}$ = fail . The grades where transformed to "points" accordingly to The Swedish National Agency for Education: $\mathrm{A}=20, \mathrm{~B}=17.5, \mathrm{C}=15, \mathrm{D}=12.5, \mathrm{E}=10, \mathrm{~F}=0,-=-10$ (http://www.studera.nu/download/18.4149f55713bbd91756380003453/gymnasietgy2011.pdf )

\section{Statistical treatment}

For the statistical analyses, a correlation analysis was conducted to identify any possible correlation between self-regulation, psychological well-being and pupil's final grades. A correlation analysis, or a "non-experimental" method means that the researcher doesn't have any influence on the independent variable or have the ability to randomizer the individuals for the conditions. The correlation analysis does not establish cause-effect; it can simply point out which variables are related to each other. The correlation coefficient $(r)$ reveals an eventual association between the variables (Borg \& Westerlund, 2012). If the correlations coefficient is near 0 , then there is no correlation, while an $r$ farther from 0 means a stronger correlation. The value of a correlation varies between -1 and $1+$ witch tells if the correlation 
is positive or negative. A negative correlation means that increasing the value in variable $\mathrm{X}$ leads to a reduction in the $\mathrm{Y}$ variable, while a positive correlation means that increasing the value in variable $\mathrm{X}$ leads to a increment in variable $\mathrm{Y}$ (Borg \& Westerlund, 2012). If the correlation coefficient shows 0 this means that there is no relationship between the variables (Borg \& Westerlund, 2012).

\section{Results}

Final grades in Swedish were positively related to two psychological well-being scales: selfacceptance $(r=.16, p=<.05)$ and personal growth $(r=.21, p=<.01)$; and to the selfregulation strategy of assessment $(r=.18, p=<.05)$. Final grades in Mathematics were positively related to three psychological well-being scales: self-acceptance $(r=.19, p=<$ $.05)$, autonomy $(r=.23, p=<.01)$, and personal growth $(r=.19, p=<.05)$; and also to assessment $(r=.24, p=<.01)$. Final grades in English were positively related to one psychological well-being scale: personal growth $(r=.17, p=<.05)$; and also to assessment $(r=.27, p=<.001)$. Final grades in Physical education were positively related to four psychological well-being scales: environmental mastery $(r=.27, p=<.001)$, self-acceptance $(r=.29, p=<.001)$, autonomy $(r=.19, p=<.05)$, and personal growth $(r=.22, p=<.01)$; and also to the self-regulation of locomotion $(r=.21, p=<.01)$. As expected, locomotion was positively related to higher psychological well-being: positive relations $(r=.33, p=<$ $.01)$, environmental mastery $(r=.50, p=<.01)$, self acceptance $(r=.39, p=<.01)$, personal growth $(r=.49, p=<.01)$ and purpose in life $(r=.44, p=<.01)$. In contrast, Assessment was only negatively related to one of the six psychological well-being scales: environmental mastery $(r=-.21, p=<.05)$. One interesting findings was that high grades in Physical education correlated with higher grades in all subjects, specially strongly related to Mathematics $(r=.76, p=<.01)$. For more details, see Table 1 . 
Table 1. Pearson's correlational between the correlations in the study; locomotion, assessment, positive relations, environmental mastery, selfacceptance, autonomy, personal growth, purpose in life and final grades.

\begin{tabular}{|c|c|c|c|c|c|c|c|c|c|c|c|c|}
\hline & 1 & 2 & 3 & 4 & 5 & 6 & 7 & 8 & 9 & 10 & 11 & 12 \\
\hline (1) Locomotion & - & & & & & & & & & & & \\
\hline (2) Assessment & .09 & - & & & & & & & & & & \\
\hline (3) Positive relations & $.33 * *$ & -.23 & - & & & & & & & & & \\
\hline (4) Environmental mastery & $.50 * *$ & $-.21 *$ & $.36 * *$ & - & & & & & & & & \\
\hline (5) Self- acceptance & $.39 * *$ & -.17 & $.47 * *$ & $.67 * *$ & - & & & & & & & \\
\hline (6) Autonomy & .16 & .01 & .10 & $.28 * *$ & $.28 * *$ & - & & & & & & \\
\hline (7) Personal growth & $.49 * *$ & .09 & $.27 * *$ & $.34 * *$ & $.41^{* *}$ & $.24 * *$ & - & & & & & \\
\hline (8) Purpose in life & $.44 * *$ & .04 & $.19 *$ & $.26 * *$ & $.22 * *$ & .01 & $.41 * *$ & - & & & & \\
\hline (9) Final grades Swedish & .14 & $.18^{*}$ & -.10 & .05 & $.16^{*}$ & .11 & $.21 * *$ & .13 & - & & & \\
\hline (10) Final grades Mathematics & .08 & $.24 * *$ & -.11 & .14 & $.19^{*}$ & $.23 * *$ & $.19^{*}$ & .10 & $.50 * *$ & - & & \\
\hline (11) Final grades English & .10 & $.27 * *$ & -.09 & -.09 & -.04 & $.06 \mathrm{~ns}$ & $.17^{*}$ & .13 & $.48 * *$ & $.35 * *$ & - & \\
\hline (12) Final grades Physical education & $.21 * *$ & $.12 \mathrm{~ns}$ & -.02 & $.27 * *$ & $.29 * *$ & $.19^{*}$ & $.22 * *$ & .13 & $.36^{* *}$ & $.76^{* *}$ & $.22 * *$ & - \\
\hline
\end{tabular}

Note: $N=160, * * p<.001, * p<.05, n s=$ non significant. 


\section{Discussion}

The purpose of this study was to investigate how high school pupils' self-regulated orientation and psychological well-being is related to academic achievement. Locomotion was positively correlated to psychological well-being and grades in Physical Education. Assessment was positively correlated with all grades with the exception of Physical Education. Earlier research shows that pupils who developed cognitive strategies in order to plan, monitor and modify their cognitive function achieve higher grades (Pintrich $\& \mathrm{~V}$. De Groot, 1990). Indeed, this type of analytical thinking is included in the construct assessment orientation. In contrast, locomotion orientation is positively related to type-A behavior, that is, a person who is impatient, competitive and likes to win (Perry et al, 1990). These characteristics might play an important role regarding Physical Education where pupils need to be competitive. These characteristics might also explain why there was no correlation between locomotion and grades in the other subjects. In work related situations, people with type-A behavior can show aggression and competitive behavior (Perry et al, 1990). This behavior might lead them to spend less time on rehearsing and studying and thinking of ways to achieve better academic results. In other words, in typical "seatwork", these pupils do not have the patience, but in physical education where some aggressiveness and competitive behavior is good they succeed better. The results also showed that grades in Physical Education positively correlated with different constructs of psychological well-being: environmental mastery, self-acceptance, autonomy, and personal growth. The grades in the other subjects (Swedish, English and Mathematics) correlated to two psychological wellbeing scales, namely, self-acceptance and personal growth. There was also a positive correlation between autonomy and grades in Mathematics.

Specifically, self-acceptance correlated with grades in Swedish, Mathematics and Physical Education. A high scorer in the construct of self-acceptance defines a person with a 
positive attitude towards the self, who accepts both good and bad sides of the self and feels positive about his or her past life. Maturity is also a part of self-acceptance (Cloninger, 2004, Ryff, 1989;). This suggests that academic achievement might lead to positive feelings and acceptance of the self or that a matured person with positive self-attitude might achieve higher grades. Personal growth was positively related to grades in all four subjects (Swedish, English, Mathematics and Physical Education). A high scorer in personal growth defines a person open to new experiences and a feeling of continual development and becoming (Ryff, 1989). These features are logically closely linked to academic achievement - the person who strives to develop their potential will likely also strive to achieve good grades with the inherent possibility of personal development through claiming new skills. With regard to the positive relationship between autonomy and grades in Mathematics it is important to notice that during lessons in Mathematics pupils often work independently with the supervision of the teacher (Skolverket, 2009). Thus, individuals that are autonomous might have an advantage in this type of learning situation. Nevertheless, most of the psychological wellbeing scales were not related to academic achievement.

It is plausible to suggest that high achieving pupils feel more pressure from parents, classmates, and themselves to do well in school and achieve high grades. When they get bad results they believe that it is a reflection on themselves, which might explain the nonsignificant relationship between the majority of psychological well-being constructs and final grades and the negative relationship between assessment and environmental mastery. Nevertheless, the negative effect of being a high achiever might also depend on whether the pupils are promotion or prevention focused (Higgins, 1997, 2001, 2012). Promotion focus means that the person is trying to achieve a positive outcome, while prevention focus means that the person is trying to minimize negative outcomes. In this context, a pupil who has a promotion focus, is trying to achieve high grades because of all the benefits that come with 
high academic achievements and because she/he associates good grades with positive feelings and being without them as painful. A pupil who has a prevention focus, is studying because it will be painful to get bad grades. That is, both pupils are trying to achieve a good grade but on different basis that might result in different feelings for the outcome.

Another important finding was the relationship between grades in physical education and grades in other subjects. Earlier research suggests that physical education increases academic achievement (Carlson et. al., 2008). Pupils who enjoy physical exercise and sports outside school might also achieve a higher level of physical fitness, which correlates with higher grades in reading and mathematics (Johnson, 2008). The present study confirms these suggestions, especially by the strong correlation between grades in Physical Education and Mathematics.

In sum, the first two hypotheses were confirmed in the differentiation between assessment and locomotion in relation to grades and psychological well-being, respectively. Assessment was indeed related to all grades, with the exception of Physical Education. This result was expected because of assessment's similarity to self-regulated learning — assessment involves strategic thinking, assessing different goals and pathways to achieve these goals (Kruglanski et al, 2000), while self-regulated learning emphasizes assessing one's own cognitions and thinking and also elaboration and constant renewal and development of one's learning strategies (Pintrich, 2004). Indeed, previous research has shown that self-regulated learning predicts higher grades in school (Corno \& Mandinach, 1983; Corno \& Rohrkemper, 1985). Locomotion, on the other hand and in concordance to earlier studies, was related to all psychological well-being scales, with the exception of autonomy. An explanation for this might be that locomotion orientation has been proved to correlate with impulsiveness (Kruglanski,,2000). Whereas a person who scores high on autonomy is determined, 
independent and able to resist peer pressure (Ryff, 1989), which means that the person can overrule impulses or desires by fully evaluating situations before acting.

The third hypothesis was only partially confirmed; grades did not correlate with all scales of psychological well-being, only with the aforementioned constructs in different constellations; self acceptance, autonomy, environmental mastery and personal growth. It is noteworthy that grades in Physical Education correlated to all of these four psychological well-being scales. There was no correlation between positive relations with others and grades or between purpose in life and grades. Ljungblad and Ölund (1970) and Lindén and colleagues (1998) showed that pupils that do not participate in discussions and interactions with their peers and teachers achieved lower grades than pupils who are more socially active. These pupils do not ask the teachers for help as often or interact as much with their classmates regarding schoolwork. Hence a positive correlation could have been expected between the psychological well-being scale of positive relations with others and grades. Nevertheless, the measures used by these researchers might not resemble Ryff's measure of social relationships. With respect to the non-relationship between purpose in life and grades, having the sense of a purpose in life is multi-faceted construct involving a wide perspective on life, love, faith, and beliefs, while grades is perhaps a too specified topic. Indeed, a person who has a high level of purpose in life has goals and a sense of direction and finds meaning in their present and past life (Ryff, 1989). This involves an understanding of the past, the present, and the future. In contrast, adolescents are more motivated to live in the present and plan less for the futurehedonistic reasoning in childhood actually declines until early adolescence and increases from middle adolescence to late adolescence (Eisenberg, 1990, 2005), that is, the age of the pupils in the present study. Moreover, previous pedagogic researchers have suggested that it is important that pupils feel that what they do is important and worth investing time in in order to feel motivated (Antonovsky, 2005). Although some pupils might find their academic 
achievement important because they want to have a good education, the absence of any correlations between purpose in life and grades might not be an indicator of a pupil's sense of purpose in life because they might find other things more important, for example a good reputation among friends (Feldt et al, 2005, Modin et al, 2011). Mansfield and Wosnitza (2010), for instance, proposed that pupils have two different goals: academic- and social goals. These researchers found that pupils cared more fore the academic goals as they were younger but when they got older they tended to care less for academic goals and more for social goals (Mansfield \& Wosnitza, 2010).

\section{Limitations}

The sample was small and therefore the results might be seen with some caution. Also, there were only two schools participating in the study. Future studies should strive for a greater selection of schools from different areas. The gender distribution is also an issue that needs to be addressed in future studies. Women, for example, tend to have higher levels of personal growth and positive relations, while no differences have been measured regarding the other constructs (Ryff, 1989). Although no differences in self-regulation orientation have been found between genders, girls usually achieve higher grades than boys (http://www.skolverket.se/press/pressmeddelanden/1997/konsskillnader-i-betygen-fortsatterflickorna-drar-upp-medelbetygen-1.47582). Finally, the Cronbach's alpha coefficients for the majority of the psychological well-being scales were low. This might affect the reliability of the study and further conclusions based on these results should be interpreted with caution until replicated using a larger and more reliable psychological well-being scale.

\section{Conclusion}

Swedish pupil's grades are lower than ever (Skolverket, 2009,PISA, 2012) and the education system is facing a huge problem that needs to be urgently addressed - young people graduating with low grades will in time affect not only the pupils but also the whole society as 
low grades leads to fewer possibilities regarding higher education and also fewer work place options. According to the report by the Programme for International Student Assessment (PISA, 2012) no other country has fallen so far behind concerning grades between the years 2009-2012 compared to the other 32 OECD countries. Reading abilities and Natural Science knowledge is significantly lower compared to earlier years. In mathematics the Swedish pupils have fallen from 494 points to 478 points, the average being 494 points. All of the other Nordic countries achieved higher scores. In reading abilities the results have fallen from 497 to 483 point, the here being 496 points; only three other countries have a lower average score. Natural Science have dropped from 495 to 485 points, the average is 501 points. Only six other countries have fewer points (PISA, 2012).

Self-regulated learning emphasizes assessment orientation, which, according to this study, is related to higher grades in Swedish, English, and Mathematics. Locomotion, on the other hand might lead to higher grades in physical education and higher psychological wellbeing. Swedish schools nowadays, however, schedule less Physical Education than ever (Ericsson, 2005); even lesser than schools in other European countries (Sveriges Radio, Ekot. 2007, interview with Suzanne Lundvall Phd in pedagogy). A dual focus approach on selfregulated learning and more physical education hours might be a part of the interventions needed to increase academic achievement while simultaneously focusing on boosting psychological well-being (see Figure 1). 


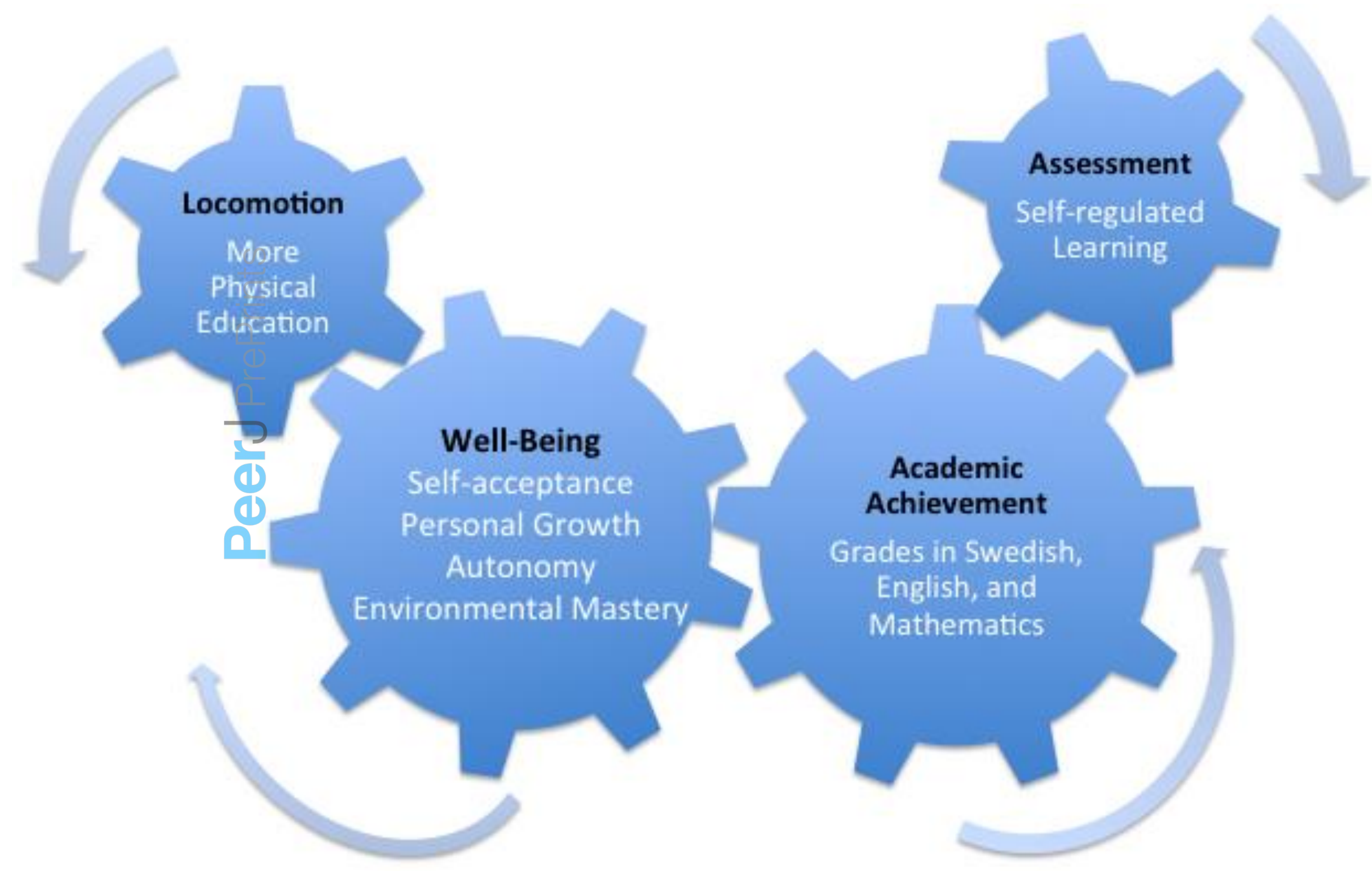

Figure 1. A dual focus approach simultaneously influencing academic achievement and psychological well-being. 


\section{References}

Antonovsky, A. (2005). Hälsans mysterium. [Mysteries of Health]. Stockholm: Natur och Kultur.

Bandura, A. (1977). Self-efficacy: Toward a unifying theory of behavioral change. Psychological Review, 84(2), 191-215. doi:http://dx.doi.org/10.1037/0033295X.84.2.191

Bandura, A. (1982). Self-efficacy mechanism in human agency. American Psychologist, 37(2), 122-147. doi:http://dx.doi.org/10.1037/0003-066X.37.2.122

Batenburg-Eddes, T.\& Jolles, J. (2013). How does emotional wellbeing relate to underachievement in a general population sample of young adolescents: a neurocognitive perspective. Frontiers Psycholigy. 4-673. doi: 10.3389/fpsyg.2013.0067

Borg, E. \& Westerlund, J. (2012). Statistik för beteendevetare: Faktabok. [Statistics for Social Scientists]. Liber

Carlson, S. A., Fulton, J. E., Lee, S. M., Maynard, L. M., Brown, D. R., Kohl,H.W., I.,II, \& Dietz, W. H. (2008). Physical education and academic achievement in elementary school: Data from the early childhood longitudinal study. American Journal of Public Health, 98(4), 721-727. doi:http://dx.doi.org/10.2105/AJPH.2007.117176

Cloninger, C. R. (2004). Feeling good: The science of well-being. New York: Oxford University Press

Corno, L., \& Mandinach, E. (1983). The role of cognitive engagement in classroom learning and motivation. Educational Psychologist, 18, 88-100.

Corno, L., \& Rohrkemper, M. (1985). The intrinsic motivation to learn in classrooms. In C. Ames \& R. Ames (Eds.), Research on motivation: Vol. 2. The classroom milieu (pp. 5390). New York: Academic Press. 
Eisenberg, N., Morris, A. S., McDaniel, B., \& Spinrad, T. L. (2009). Moral cognitions and prosocial responding in adolescence. John Wiley \& Sons Inc, Hoboken, NJ.

Eisenberg, N. (2006). Introduction. John Wiley \& Sons Inc, Hoboken, NJ. Retrieved from http://search.proquest.com/docview/621353379?accountid=11162

Ericsson, I. (2005). Rör dig - lär dig. [Move - Learn]. Stockholm: SISU Idrottsböcker.

Feldt, T., Kokko, K., Kinnunen., U., \& Pulkkinen, L (2005). The role of Family Background, School success, and Career Orientation in the Development of Sense of Coherence. European Psychologist, 10(4), 298-308.

Garcia, D., Archer, T., Moradi, S., \& Andersson-Arntén, A-C. (2012). Exercise Frequency, High Activation Positive Affectivity, and Psychological Well-Being: Beyond Age, Gender, and Occupation. Psychology, 3, 328-336. doi: 10.4236/psych.2012.34047.

Garcia, D., \& Siddiqui, A. (2009). Adolescents' psychological well-being and memory for life events: Influences on life satisfaction with respect to temperamental dispositions. Journal of Happiness Studies, 10(4), 407-419. doi:http://dx.doi.org/10.1007/s10902008-9096-3

Giacomantonio, M., Mannetti, L., \& Pierro, A. (2013). Locomoting toward well-being or getting entangled in a material world: Regulatory modes and affective well-being. Journal of Economic Psychology, 38, 80-89.

doi:http://dx.doi.org/10.1016/j.joep.2012.07.003

Gollwitzer, P. M. (1990). Action phases and mind-sets. In E. T. Higgins \& R. M. Sorrentino (Eds.), Handbook of motivation and cognition: Foundations of social behavior (Vol. 2,pp. 53-92). 
Heckhausen, J. (2000). Developmental regulation across the life span: An action-phase model of engagement and disengagement with developmental goals, 131, 213-231. Elsevier Science, New York, NY.

Higgins, E. T. (1997). Beyond pleasure and pain. American Psychologist, 52, 1280-1300.

Higgins, E. T. (2001). Promotion and prevention experiences: Relating emotions to nonemotional motivational states. In J. P. Forgas (ed.), Handbook of affect and social cognition (pp. 50-74). New Jersey: Erlbaum.

Higgins, E. T., Kruglanski, A. W., \& Pierro, A. (2003). Regulatory mode: Locomotion and assessment as distinct orientations. 35, 293-344. Elsevier Academic Press, San Diego, CA. doi:http://dx.doi.org/10.1016/S0065-2601(03)01005-0

Higgins, E. T. (2012). Beyond pleasure and pain: How motivation works. New York, NY, US: Oxford University Press, New York, NY.

Higgins, E. T. (2012). Beyond pleasure and pain: How motivation works Oxford University Press, New York, NY.

Jimmefors, A. (2013). Variationer av välbefinnande och självreglering hos gymnasieelver med olika affektiva profiler. Göteborgs Universitet: Psykologiska institutionen, Göteborg.

Johnson, J. S. (2008). The effect of school-based physical activity and obesity on academic achievement. (Order No. AAI3337521, Dissertation Abstracts International Section A: Humanities and Social Sciences, 4277.

Kessler, R. C., Foster, C. L., Saunders, W. B., \& Stang, P. E. (1995). Social-consequences of psychiatric-disorders. 1. Educational-attainment. Am. J. Psychiatry 152, 1026-1032.

Kjell, O. N. E., Nima, A. A., Sikström, S., Archer, T., \& Garcia, D. (2013). Iranian and Swedish Adolescents: Differences in Personality Traits and Well-Being. PeerJ 1:e197. doi: 10.7717 peerj.197. 
Kruglanski, A. W., Thompson, E. P., Higgins, E. T., Atash, M. N., Pierro, A., Shah, J. Y., \& Spiegel, S. (2000). To "do the right thing" or to "just do it": Locomotion and assessment as distinct self-regulatory imperatives. Journal of Personality and Social Psychology, 79(5), 793-815. doi:http://dx.doi.org/10.1037/0022-3514.79.5.793

Kruglanski, A. W., Pierro, A., Higgins, E. T., \& Capozza, D. (2004). "On the move” or "staying put": Locomotion, need for closure and reactions to organizational change. Unpublished manuscript. University of Maryland.

Lewin, K., Dembo, T., Festinger, L., \& Sears, P. S. (1944). Level of aspiration. In J. McHunt (Ed.), Personality and the behavior disorders (Vol. 1, pp. 333-378). New York: Ronald Press.

Lindén, M., Norström, M. \& Nyblom, K. (1998). Våga tala: om studenter med talängslan och Studenthälsans yttrandeträningskurser. Uppsala: Studenthälsan.

Ljungblad, T. \& Ölund, K. (1970). Talängslan - en faktor att räkna med. Svenskläraren, $n r 2$, $10-13$.

Mansfield, Caroline F., \& Wosnitza, Marold (2010). Motivation goals during adolescence. A cross-sectional perspective. Issues in Educational Research, 20(2), 149-165.

Mirowsky, J., \& Ross, C. (2003). Education, Social Status, and Health. New York, NY: Aldine de Gruyter

Modin, B., Östberg, V., Toivanen, S., \& Sundell, K. (2011). Psychosocial working conditions, school sense of coherence and subjective health complaints. A multilevel analysis of ninth grade pupils in the Stockholm area. Journal of Adolescence, 34, 129-139.

Perry, A. R., Kane, K. M., Bernesser, K. J., \& Spicker, P. T. (1990). Type A behavior, competitive achievement-striving, and cheating among college students. Psychological Reports,_66(2),_459-465. 
Pierro, A., Giacomantonio, M., Pica, G., Kruglanski, A. W., \& Higgins, E. T. (2013). Locomotion and the preference for multi-tasking: Implications for well-being. Motivation and Emotion, 37(2), 213-223. doi:http://dx.doi.org/10.1007/s11031-012$9300-y$

Pintrich, P. R., \& de Groot, E. V. (1990). Motivational and self-regulated learning components of classroom academic performance. Journal of Educational Psychology, 82(1), 33-40. doi:http://dx.doi.org/10.1037/0022-0663.82.1.33

Pintrich, P. R. (2004). A conceptual framework for assessing motivation and self-regulated learning in college students. Educational Psychology Review, 16(4), 385-407.

Ryff, C. D. (1989). Happiness is everything, or is it? Explorations on the meaning of psychological well-being. Journal of personality and Social Psychology, 57, 10691081.

Ryff, C. D. (1995). Psychological well-being in adult life. Current Directions in Psychological Science, 4, 99-104.

Skolverket(2009). Försämring av gymnasieelevers kunskaper i matematik och fysik. http://www.skolverket.se/press/pressmeddelanden/2009/kraftig-forsamring-avgymnasieelevernas-kunskaper-i-matematik-och-fysik-1.91259

Skolverket (2012)_Sammanfattning av PISA-undersökning. http://www.skolverket.se/publikationer?id=3126Skolverket (2012). Betyg i grundskolan årskurs_9_läsår_2012/13. http://www.skolverket.se/statistik-ochutvardering/statistik/grundskola/betyg-ak-9.

Sverigesradio (2013). För lite idrott i skolan tycker forskare. http://sverigesradio.se/sida/artikel.aspx?programid=83\&artikel=1188963. 